\title{
A unique insight into the incidence of rugby injuries using referee replacement reports
}

\author{
J C M Sharp, G D Murray, D A D Macleod
}

\begin{abstract}
Objectives-To obtain further information on the incidence of injuries and playing positions affected in club rugby in Scotland.

Methods-Routine reports of injury (permanent) and blood (temporary) replacements occurring in competitive club rugby matches by referees to the Scottish Rugby Union during seasons 1990-1991 to 1996-1997 were analysed.

Results-A total of 3513 injuries (87 per 100 scheduled matches) and 1000 blood replacements $(34$ per 100 scheduled matches) were reported. Forwards accounted for $60 \%$ of the injury and $72 \%$ of the blood replacements. Flankers and the front row were the most commonly replaced forwards while wing and centre three quarters were the most vulnerable playing positions among backs. The incidence of injury replacements increased as the match progressed up until the last 10 minutes when the trend was reversed. Blood replacements showed a different pattern with $60 \%$ occurring during the first half of the match.

Conclusion-The most important finding of the study was reliability of referees in documenting the vulnerability of certain playing positions, and the timing when injuries took place, thus assisting coaches and team selectors when choosing replacement players for competitive club and representative rugby matches. This study re-emphasises the need for continuing epidemiological research.

(Brf Sports Med 2001;35:34-37)
\end{abstract}

Keywords: rugby injuries; referee replacement reports; Scottish Rugby Union

During the 1970s, rugby union was criticised by the media alleging an increase in aggressive and deliberately dangerous play. Numerous clinical and epidemiological studies of rugby injury were subsequently reported from the British Isles ${ }^{1-5}$ and overseas, ${ }^{6-10}$ identifying an apparently greater incidence and severity of injury and the vulnerability of certain playing positions, in particular front row forwards.

The Scottish Rugby Union (SRU) led the way in the British Isles, following the introduction of competitive club rugby based on national leagues in Scotland in 1973, with a series of research projects which collected information about the nature, incidence, and causes of injury in an effort to enhance prevention and treatment. These studies included establishing the first national coordinated survey on injuries occurring during competitive club rugby ${ }^{11}$ in Scotland, reviewing the accident and emergency department records of all injured players in the Scottish Borders during the season 1990-1991 (H J Vander Post, personal communication), and encouraging clubs to report to the SRU all players admitted to hospital or dying as a result of playing or practising rugby. More recent epidemiological studies established jointly with Edinburgh University Department of Public Health Sciences reviewed injuries occurring in adult and school boy rugby in the Scottish Borders and Edinburgh schools. ${ }^{12}$

A further initiative was established in 19881989 when referees were asked to record all replacements made for injured players during club matches in the competitive leagues. This paper reports the findings from this study, which we believe to be unique, reviewing 3513 injury and 1000 blood replacement reports over seven seasons of Scottish Rugby (19901991 to 1996-1997).

\section{Materials and methods}

In the season 1988-1989, rugby referees in Scotland were required to notify the SRU of any player who had to leave the field as the result of injury or other "medical" reason-for example, hypothermia-for whom a replacement player was permitted. The quality of

\section{SRU CHAMPIONSHIP \\ Division .........................} RESULT CARD

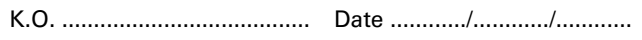

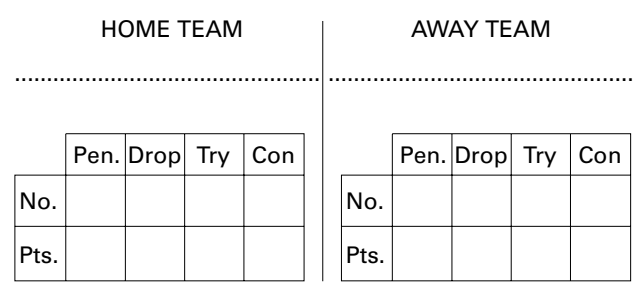
FINAL

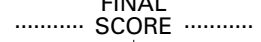

REPLACEMENTS

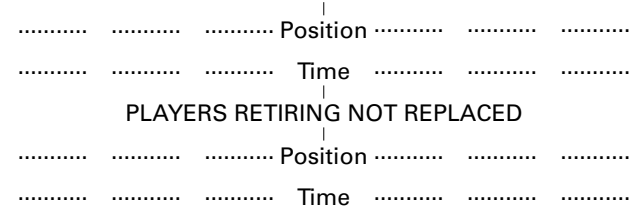

BLEEDING PLAYERS RETIRING TEMPORARILY

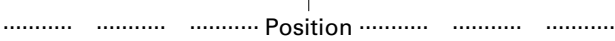

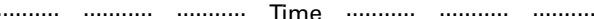

Referee's Signature

Name

Club

Figure 1 Scottish Rugby Union result card.
Scotland, UK

Accepted 24 August 2000 


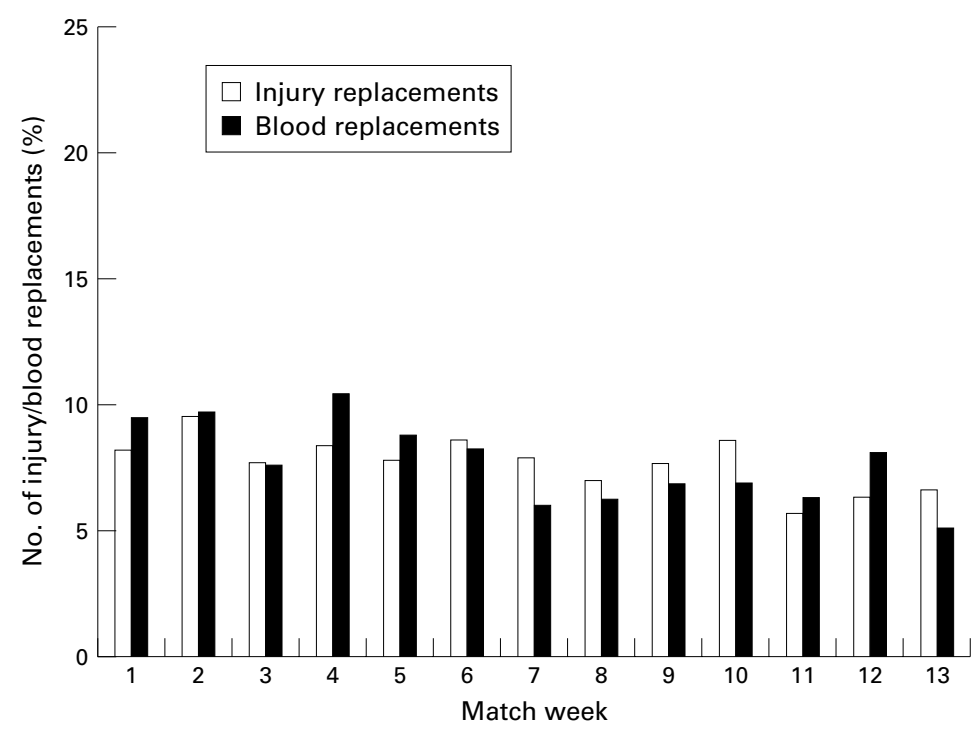

Figure 3 Injury (1990-1995) and blood (1993-1995) replacements by match week number. bleeding, or illness. As a result, the value of referee replacement reports in monitoring the occurrence of rugby injuries was diminished. Referees continued to report temporary blood replacements for a further season until the end of 1996-1997 but this has subsequently been discontinued.

The data presented are purely descriptive, without any formal statistical analysis. To make replacement rates comparable, they are summarised as replacements per 100 scheduled matches, or, when reporting on specific playing positions, as replacements per player per 100 scheduled matches. This allows for the fact that the reporting of injury and blood replacements does not span exactly the same seasons, that the number of matches per season varies, and that the different positions have one or two players per team (and hence two or four players per match).

\section{Results}

Reports on 3513 injury replacements (87 per 100 scheduled matches) and 1000 temporary blood replacements (34 per 100 matches) were received by the SRU from referees of competitive club matches during the seven seasons 1990-1991 to 1996-1997. The number of reports of injury replacements increased from 410 in 1990-1991 (64 per 100 matches) to 554 in 1994-1995 (87 per 100 matches), when up to three replacements were permitted per match for each team. The total number of injury replacements increased to 989 in 1995-1996 (116 per 100 matches) when the number of replacements permitted had been increased to four per team and the playing season extended. Reports of temporary replacement of players because of bleeding varied from season to season, peaking at

Table 1 Type of replacement by playing position (backs/forwards) and season 1990-1997

\begin{tabular}{|c|c|c|c|c|c|c|c|c|}
\hline & $1990-1991$ & 1991-1992 & $1992-1993$ & 1993-1994 & 1994-1995 & 1995-1996 & $1996-1997$ & Totals \\
\hline \multicolumn{9}{|c|}{ "Injury" replacements (permanent) } \\
\hline Backs & 164 & 185 & 225 & 203 & 228 & 385 & - & $1390(40 \%)$ \\
\hline Forwards & 245 & 263 & 299 & 380 & 325 & 600 & - & $2112(60 \%)$ \\
\hline Unspecified & 1 & - & 3 & 2 & 1 & 4 & - & 11 \\
\hline Totals & 410 & 448 & 527 & 585 & 554 & 989 & - & 3513 \\
\hline \multicolumn{9}{|c|}{ "Blood" replacements (temporary) } \\
\hline Backs & - & - & - & 56 & 62 & 91 & 72 & $281(28 \%)$ \\
\hline Forwards & - & - & - & 175 & 139 & 230 & 175 & $719(72 \%)$ \\
\hline Totals & & & & 231 & 201 & 321 & 247 & 1000 \\
\hline Totals & 410 & 448 & 527 & 816 & 755 & 1310 & 247 & 4513 \\
\hline
\end{tabular}

Table 2 "Injury" and "blood" replacement reports by individual playing positions, 1990-1997

\begin{tabular}{|c|c|c|c|c|c|c|}
\hline \multirow[b]{2}{*}{ Playing position } & \multicolumn{3}{|c|}{ Injury replacements 1990-1996 } & \multicolumn{3}{|c|}{ Blood replacements 1993-1997 } \\
\hline & Number & $\begin{array}{l}\text { Rate per player } \\
\text { per } 100 \text { matches }\end{array}$ & Rank order & Number & $\begin{array}{l}\text { Rate per player } \\
\text { per } 100 \text { matches }\end{array}$ & Rank order \\
\hline \multicolumn{7}{|l|}{ Backs } \\
\hline Full back & 182 & 2.3 & 10 & 37 & 0.6 & 8 \\
\hline Wing $3 / 4$ & 419 & 2.6 & 6 & 54 & 0.5 & 10 \\
\hline Centre & 401 & 2.5 & 7 & 88 & 0.7 & 7 \\
\hline Stand-off & 191 & 2.4 & 9 & 33 & 0.6 & 9 \\
\hline Scrum half & 197 & 2.4 & 8 & 69 & 1.2 & 6 \\
\hline \multicolumn{7}{|l|}{ Forwards } \\
\hline Prop & 554 & 3.4 & 2 & 183 & 1.5 & 3 \\
\hline Hooker & 244 & 3.0 & 3 & 78 & 1.3 & 4 \\
\hline 2nd row & 446 & 2.9 & 5 & 144 & 1.2 & 5 \\
\hline Flanker & 633 & 3.9 & 1 & 212 & 1.8 & 1 \\
\hline No 8 & 235 & 2.9 & 4 & 102 & 1.7 & 2 \\
\hline \multirow[t]{2}{*}{ Unspecified } & 11 & & & & & \\
\hline & 3513 & & & 1000 & & \\
\hline
\end{tabular}


Table 3 Injury replacement by division (I-VII), 1990-1991 to 1994-1995

\begin{tabular}{|c|c|c|c|c|c|c|c|c|c|c|c|c|c|c|}
\hline \multirow[b]{2}{*}{ Division } & \multicolumn{14}{|c|}{ Match week number } \\
\hline & 1 & 2 & 3 & 4 & 5 & 6 & 7 & 8 & 9 & 10 & 11 & 12 & 13 & Totals (\%) \\
\hline I & 43 & 27 & 15 & 23 & 21 & 41 & 27 & 23 & 26 & 29 & 18 & 22 & 25 & $340(13.4)$ \\
\hline II & 29 & 46 & 30 & 35 & 33 & 34 & 30 & 37 & 24 & 38 & 17 & 24 & 27 & $404(16.0)$ \\
\hline III & 26 & 40 & 40 & 29 & 31 & 32 & 26 & 32 & 27 & 35 & 22 & 30 & 22 & $392(15.5)$ \\
\hline IV & 25 & 40 & 24 & 34 & 30 & 34 & 39 & 20 & 33 & 29 & 26 & 35 & 33 & $402(15.9)$ \\
\hline $\mathrm{V}$ & 33 & 38 & 41 & 40 & 36 & 33 & 35 & 27 & 36 & 38 & 27 & 24 & 26 & $434(17.2)$ \\
\hline VI & 27 & 29 & 25 & 22 & 25 & 18 & 20 & 25 & 25 & 30 & 20 & 9 & 10 & $285(11.3)$ \\
\hline VII & 24 & 19 & 20 & 29 & 20 & 26 & 22 & 12 & 24 & 18 & 14 & 14 & 25 & $267(10.6)$ \\
\hline Totals & 207 & 239 & 195 & 212 & 196 & 218 & 199 & 176 & 195 & 217 & 144 & 158 & 168 & 2524 \\
\hline
\end{tabular}

321 in 1995-1996 (38 per 100 matches) but decreasing to 247 ( 29 per 100 matches) in the following season (table 1).

Of the 3513 injury replacements, 2112 $(60 \%)$ involved forwards and 1390 (40\%) backs; in 11 reports no playing position was identified. In every season, forwards were consistently injured more often than backs (interseasonal range 57-65\%) even allowing for the 8:7 excess of forwards over backs. This pattern was even more apparent for the 1000 blood replacements, of whom $72 \%$ were forwards (interseasonal range 69-76\%) (table 1).

Flankers (3.9 per individual player per 100 matches) followed by prop forwards (3.4) were the playing positions most often replaced as a result of injury. Among backs, wing (2.6) and centre three quarters (2.5) predominated. Full back (2.3), stand off (2.4), and scrum half (2.4) were the least commonly replaced players, although the replacement rates were very similar for all back positions. Flankers (1.8 per player per 100 matches) and the Number 8 (1.7), all in the back row of the scrum, were the players most often requiring attention to bleeding wounds, followed by each of the other forward positions. Scrum half (1.2) and centre three quarters (0.7) were the backs most commonly affected (table 2).

Injury incidence increased as the match progressed up to the last 10 minutes, when the trend was reversed (fig 2). In the 3509 instances when the time of an injury was specified, 1068 (30\%) occurred during the first half of the match and $2441(70 \%)$ in the second half.

Blood replacements showed a different pattern, with $598(60 \%)$ of bleeding injuries occurring during the first half of the match decreasing to $402(40 \%)$ in the second half (fig 2).

While the incidence of injury and bleeding replacements did not vary substantially throughout the season, there was a notable decrease in the number of injury replacements, in particular during the later weeks of the season (fig 3, table 3).

In the first five seasons (1990-1991 to 1994-1995) a total of 2524 injury replacements were reported by referees, with the greatest number recorded in division V (434) followed by division II (404), division IV (402), division III (392), and division I (340). The lowest incidence of reports was in divisions VI and VII (table 3) where the availability of replacement players was less likely. This distribution was less clear in the seasons after the changes in the number of replacements permit- ted per team (from three to four) and in the format of competitive club rugby in Scotland during season 1995-1996.

Comparison of blood replacement reports by divisions during seasons 1993-1994 and 1994-1995 and later seasons 1995-1996 and 1996-1997 similarly indicated a smaller number being used in lower divisions.

\section{Discussion}

Every epidemiological surveillance system has individual advantages and disadvantages, with under-reporting a consistent feature. In this unique study using routine referee reporting, compliance was almost $100 \%$ because of their requirement to complete result cards and forward them to the SRU after every championship match. Any shortfall was attributed to reports being telephoned in lieu of written completion of a card. In addition, the data obtained from routine reports was inexpensive and straightforward to administer. The disadvantage was its failure to obtain information with regard to the phase of play and the nature and cause of the injury sustained as well as being limited to first XV teams playing in the senior leagues of club rugby in Scotland.

In the season 1995-1996, the format of competitive rugby in Scotland was changed from the previous structure of seven divisions each including 14 clubs (a total of 98 clubs) to four premiership divisions each of eight clubs and seven national leagues each of 10 clubs, thus increasing the total number of clubs involved in competitive rugby to 102 . As a result the comparison of the frequency of replacements at different levels of competitive rugby was thereafter more difficult to undertake.

This study identified that $50 \%$ of injury replacements occurred in the six matches played in September and October, the first two months of the season. The remaining matches in the league competitions were spread out during the rest of the season. Garraway and Macleod $^{12}$ showed that injuries were most common during the first two months of the season, quoting a period prevalence of 15.2 per 1000 playing hours, amounting to $60 \%$ of all injuries which occurred in the season, compared with $12.3 \%$ in March and April. Similar early season injury patterns have been reported including a South African analysis of injuries in school boy rugby. ${ }^{8}$

The number of temporary and permanent injury replacements reported at different levels of rugby nevertheless suggest that, although 
there is a greater incidence of injuries in the upper echelons of Scottish rugby, this is not a major feature. Although a full complement of replacement players is less likely to be a feature at lower levels of competitive rugby, a degree of under-reporting by referees in the lower leagues must also be borne in mind.

The observed decrease in the number of injury replacements during the last 10 minutes of matches can reasonably be attributed to no further replacements being available and/or injured players playing on with only a few minutes of a match remaining. Similarly a reduced availability of replacements for bleeding injuries during the later stages of a match would not be entirely unexpected.

In addition to confirming the feasibility of this approach to analysing rugby injuries, perhaps the second most important finding from the study was to show once again the incidence of injury among certain playing positions, in particular the flankers and front row forwards, thus assisting team coaches and selectors when choosing the replacements most likely to be required for injured players. It is not surprising that bleeding injuries more or less followed a similar pattern. In effect, the use of up to 87 permanent replacements for injuries per 100 scheduled matches and 38 temporary replacements for bleeding injuries was remarkably low, before the law changes in the game of rugby entitling the use of replacements for tactical reasons.

There remains a continuing need for further epidemiological studies into the incidence, distribution, and nature of injuries in rugby union, ${ }^{12}$ along with the establishment of properly funded case registers reporting key injuries. ${ }^{14}$ The referee in rugby union has an increasingly wide range of responsibilities because of the complex nature of the laws of the game. It is becoming increasingly difficult for the referee to maintain an accurate record of replacements of players for injury or tactical reasons as a result of recent law changes. It is suggested therefore that a touch judge, or fourth official in those matches where one was available, could record the timing and position of injured or bleeding players, adding this information to the referee's report card at the end of a match. This invaluable source of epidemiological information would therefore not be lost as a research tool and perhaps could be developed further at representative and international level. We thank the SRU and their referees for their support and
assistance throughout the period of the study. Our thanks are also due to Mrs Derena Ritchie for typing the manuscript.

1 Durkin TE. A survey of injuries in a first class rugby union football club from 1972-76. Br F Sports Med 1977;11:7-11. Davies JE, Gibson T. Injuries in rugby union football. $B M \mathcal{F}$ 1978;2:1759-61.

3 Hoskins T. Rugby injuries to the cervical spine in English schoolboys. Practitioner 1979;223:365-6.

4 Addley K, Farren J. Irish rugby injury survey: Dungannon Addley K, Farren J. Irish rugby injury survey: Dunganno
Football Club, 1986-87. Br f Sports Med 1988;22:22-4.

5 Sparks JP. Half a million hours of rugby football. The injuries. Br f Sports Med 1981;15:30-2.

6 Dalley DR, Laing DR, Rowberry JM, et al. Rugby injuries: Dalley DR, Laing DR, Rowberry JM, et al. Rugby injuries: an epidemiological survey, Christchurch,

7 Burry HC, Calcinai CJ. The need to make rugby safer. BMF 1988;296:149-50.

8 Roux CE, Noakes TD. The epidemiology of schoolboy injuries. In: Intermittent high intensity exercise. London: $\mathrm{E} \& \mathrm{~F} \mathrm{~N}$ Spon, 1993;1:419-26.

9 Clark DR, Roux C, Noakes TD. A prospective study of the incident and nature of injuries to adult rugby players. $S$ Afr Med f 1990;77:559-62.

10 Dalley DR, Laing DR, McCartin PJ. Injuries in rugby football Christchurch 1989. New Zealand Fournal of Sports Medicine 1992;20:2-5.

11 Sharp JCM, Macleod DAD. Injuries in competitive rugby football in Scotland. Update 1981;2.2:1355-61.

12 Garraway WM, Macleod DAD. Epidemiology of rugby football injuries. Lancet 1995;345:1485-7.

13 Upton PAH, Roux CE, Noakes TD. Inadequate pre-season preparation of school boy rugby players: a survey of players at 25 Cape Province high schools. S Afr Med $\mathcal{F}$ 1996;86:531-3.

14 Garraway WM, Macleod DAD, Sharp JCM. Rugby injuries: the need for case registers. BMF 1991;303:1082-3.

\section{Take home message}

Sports medicine must endeavour to make a positive contribution to player safety, irrespective of the sport involved. Recommendations to players, coaches, officials, and governing bodies designed to minimise illness or injury in sport should be based on reliable data. Inviting match officials to record basic details about players unable to complete a match because of injury has proved to be an accurate source of information. 


\section{LETTERS TO THE EDITOR}

The ups and downs of high altitude mountaineering

EDIToR,-Professor Craig Sharp delighted us with a recent account of his world record ascent of Mt Kilimanjaro in the 1960s and voiced his concerns about the physiological dangers inherent in such a feat; ${ }^{1}$ the madness and exuberance of youth! It is interesting to note that this record was established during the height of one of the most unforgettable debates in mountaineering history provoked by the initial uncertainties of Barcroft, Margaria, and Henderson, the possibility of an "oxygenless" ascent of Mt Everest. The epochal ascent without supplemental oxygen by Messner in 1978 subsequently put paid to any speculation and reinforced what $\mathrm{T} \mathrm{H}$ Huxley (1825-1895) once remarked "The great tragedy of science; the slaying of a beautiful hypothesis by an ugly fact!"

The "get up and get down" philosophy of mountaineering has become an increasingly popular practice among enthusiasts who are either pitting their physical attributes against the stopwatch or, as Messner would maintain, merely limiting their time spent in the "death zone". Perhaps the most astonishing feat of all was achieved during an Italian expedition to Mt Everest in May 1996 when Hans Kammerlander summited via the North Col in a record time of 17 hours and then descended to basecamp on skiis! However, although extending the envelope of human endurance, the risks inherent in such an extreme sport simply cannot be ignored.

For example, research in our laboratory has recently indicated a pronounced increase in metabolic biomarkers of free radical and skeletal muscle damage at $5100 \mathrm{~m}$ due primarily to the oxidative and reductive stress imposed by physical exercise and environmental hypoxia respectively. We have also incriminated free radicals in the pathophysiology of acute mountain sickness and endothelial dysfunction at high altitude. ${ }^{2}$ Thus, when one considers the average hourly ascent rates by Sharp and Kammerlander of about $611 \mathrm{~m}$ and about $215 \mathrm{~m}$ respectively compared with the more leisurely $12-30 \mathrm{~m}$ typically encountered during a Himalayan expedition, the potential for suffering at the hands (or more appropriately electrons!) of these ubiquitous biomolecules is all too apparent. Free radical generation may be further compounded during a rapid as opposed to a steady controlled descent because of the mechanical trauma of eccentric muscle contractions and greater increase in arterial $\mathrm{pO}_{2}$ implicit in reoxygenation injury.

But how do these mountaineers achieve such remarkable feats and survive to tell the tale when others falter even at the slightest whiff of hypoxia? The fact that Professor Sharp was effectively a native highlander at the time of his record suggests that acclimatisation may have conferred at least some protection. Or perhaps he is one of the genetically gifted with the I allele of the ACE gene recently associated with improved performance at high altitude? ${ }^{3}$ While this remains a riddle wrapped in a mystery inside an enigma, it would seem wise counselling to ensure that those antioxidants are packed before visiting one of nature's wonders!

DAMIAN MILES BAILEY Senior Lecturer in Physiology, 1998 Mt Kanchenjunga Medical Expedition, clo Hypoxia Research Unit, Health and Exercise Sciences Research Laboratory,

University of Glamorgan, Pontypridd CF37 1DL, UK

1 Sharp C. Exercise at altitude. Br $\mathcal{F}$ Sports Med 2000;34:404

2 Bailey DM, Davies B, Davison G, et al. Free radical damage at high-altitude; isolating the
source and implications for the pathophysiolsource and implications for the pathophysiol-
ogy of acute mountain sickness. Newsletter of the ogy of acute mountain sickness. Newsletter of the International

3 Montgomery HE, Marshall RM, Hemingway $\mathrm{H}$, et al. Human gene for physical performance. Nature 1998;393:221-2.

\section{Professionalism and injuries in rugby} union

EDIToR,-Garraway et al $^{1}$ are to be congratulated on their meticulous investigation of the incidence of rugby injuries.

Rugby has a very high incidence of injuries. Garraway et al state: "An injury episode occurred in a professional team for every 59 minutes of competitive play" - that is, one serious injury among 30 professional players every 59 minutes. Of greater concern is the fact that Garraway et al reported two neck dislocations, one of which resulted in permanent neurological damage, in this recent paper compared with nil in the earlier one. ${ }^{2}$

The question of rugby injuries is an emotive one and I have been concerned, over the years, with the incidence of severe injuries causing tetraplegia. The fact that professional players are suffering a greater number of injuries was apparent from my own researches in $1984^{3}$ on 67 patients with tetraplegia whom I treated. I followed this up in $1992^{4}$ and $1994^{5}$ and found that there was a direct correlation between the standard of play, the fitness of the player, and the number of injuries. My findings suggested that greater skill does not provide protection, as six of the players injured were first class players and there are only about 2000 such players in England compared with a total of 400000 players at all standards. The large number of injuries sustained on tours supports the view that the stronger and fitter the player, the greater the likelihood of an injury occurring.

The analogy with vehicle accidents is striking, whereby the forces involved and the speed of deceleration are the major factors in determining the severity of the injury. This is confirmed in the first class game where the players run faster and are bigger and heavier and impact with greater force.

Schneider ${ }^{6}$ made a separate study of this among American players. He found that 141 serious injuries occurred among 780000 high school football players, 34 among 70000 university footballers, and 14 among 4500 professional players, whereas, in Sandlot football, an unskilled form of the game (where players do not wear protective clothing!), 26 injuries occurred among 1645000 players. He concluded that unskilled players do not play as hard as highly skilled or professional athletes and that the greater degree of force and skill exaggerates the likelihood of injury.

Garraway et $a l^{1}$ say "where valid comparisons can be made, it appears that professional rugby union produces higher injury rates than professional rugby league." This is not in accord with my earlier findings. It has been suggested that rugby league is a much safer game as the ruck and maul have been abolished. However, the incidence of injury is four players out of 26000 with broken necks for rugby league versus five players out of 500000 for rugby union, which does not support this claim.

J R SILVER Fellow of the Institute of Sports Medicine Consultant in Spinal Injuries, National Spinal Injuries Centre, Stoke Mandeville Hospital, Bucks, UK

1 Garraway WM, Lee AJ, Hutton SJ, et al. Impact rugby union. Br $\mathcal{F}$ Sports Med 2000;34:348-51.

2 Garraway M, Macleod D. Epidemiology of rugby football injuries. Lancet 1995;345:1485-7.

3 Silver JR. Injuries of the spine sustained in rugby. Br f Sports Med 1984;228:37-43.

4 Silver JR. Injuries of the spine sustained during rugby. Br f Sports Med 1992;26:253-8.

5 Silver JR. The prevention of spinal injuries in Silver JR. The prevention of spinal injuries
rugby football. Paraplegia 1994;32:442-53.

6 Schneider RC. Head and neck injuries in football: mechanisms, treatment, and prevention. Baltimore: Williams and Wilkins, 1973.

\section{Effectiveness of stretching to reduce} injury

There appears to be a conflict of ideas in two of the leaders in the October issue of the journal. Reid and McNair ${ }^{1}$ state on page 322 that "it is important for rowers to include hamstring stretches in their training programmes", their argument being that stiffness of the hamstrings would prevent pelvic rotation and increase the likelihood of back pain. Shrier, ${ }^{2}$ however, demonstrates that there is no evidence that stretching before exercise reduces injury.

May I suggest that these views are not necessarily incompatible. Firstly, it would seem to me that there may be a difference between stretching abnormally tight tissues into a normal range of motion as opposed to stretching normal tissues into an excessive range. Is this difference specified in the studies of the effects of stretching on injury prevention referred to by Shrier? Perhaps it is a semantic quibble, but what is stretching? Secondly, Reid and McNair illustrate the concept of the kinetic chain. Did the studies of the ineffectiveness of stretching look at stretching one link in the kinetic chain to reduce injury elsewhere or were they concerned with merely local effects?

P E SCHUR

Wiggo Cottage, 135 Main Road Wybunbury, Nantwich Cheshire CW5 7LR, UK

1 Reid DA, McNair PJ. Factors contributing to low back pain in rowers. Br $\mathcal{F}$ Sports Med 2000;34:321-2

2 Shrier I. Stretching before exercise: an evidence based approach. Br $\mathcal{F}$ Sports Med 2000;34:324-5.

\section{BOOK REVIEWS}

Introduction to clinical neurology. 2nd ed. Douglas J Gelb. (Pp 386; £22.50.) Oxford: Butterworth-Heinemann, 2000. ISBN 07506-7202-1.

General practitioners who have long lost the art of performing and applying the findings of 
a neurological examination will find this concise American text a useful addition to the practice library, as an easily understood reference source.

The book is primarily written for medical students, and achieves this aim as it is an excellent introductory text. It contains numerous practical tips for carrying out a thorough neurological examination in one excellent chapter. Fortunately, the text also contains many shortened or modified versions of aspects of the full examination, which will allow the physician or student to identify significant abnormalities, and then apply the findings appropriately. Challenges are set throughout the book, such as "Where's the lesion?", and discussion of case histories provides practical and applicable examples of application of the examination and accurate diagnosis. The format of these case histories is rather confusing initially, but a little persistence enables the reader to learn a great deal from their application.

Common neurological disorders are covered broadly, but not in much depth, as the title of the book suggests. There is good coverage of new drugs and therapies for multiple sclerosis and Parkinson's disease for those doctors who may have fallen behind the rapid advancement of neurological treatments.

\section{Analysis}

Presentation

Comprehensiveness

Readability

Relevance

Evidence basis

Total

MARK RIDGEWELI Kings Road Surgery, Mumbles, Swansea SA3 4AF,
Wales, UK

Tendinitis: its etiology and treatment. William D Stanish, Sandra Curwin and Scott Mandell. (Pp 140; £34.95) Oxford University Press, 2000.

ISBN 0192635822.

I must say that I liked this book. In a most logical and readable fashion it set about what can be a rather dour, but yet most clinically important topic. Opening chapters on the normal tendon and the etiology of tendinitis were followed by more clinically and exercise related areas. Initial graphs and diagrams were simple and clear but some of the later clinical illustrations could have been improved by the use of photographs or colour.

The renowned authors combine well to use their obvious clinical experience to give a balanced viewpoint of both conservative and surgical treatments, with the emphasis being on rehabilitation. All treatment options are assessed and the evidence for their choice is given. Throughout, any statements are backed up by suitable references and with suggestions for further reading.

The clinical chapters cover common presentations-Achilles, jumper's knee, humeral epicondylitis - and take the reader logically through pathology, etiology, diagnosis, and treatment. The book finishes with an outline of the eccentric exercise programme used in the authors' Nova Scotia Sports Medicine Clinic and analyses its application.

At 140 pages, this book is concise and therefore easily readable. Although the title does not mention exercise or sport, throughout the book there are many references to the athlete. All in all, this is an excellent book which will be of benefit to any sports or musculoskeletal practitioner.

$\begin{array}{lr}\text { Analysis } & \\ \text { Presentation } & 18 / 20 \\ \text { Comprehensiveness } & 17 / 20 \\ \text { Readability } & 19 / 20 \\ \text { Relevance } & 18 / 20 \\ \text { Evidence basis } & 17 / 20 \\ \text { Total } & 89 / 100\end{array}$

B THOMPSON

Sports and Orthopaedic Medicine Clinic, Craigavon Area Hospital, N. Ireland

Chronic ankle pain in the athlete. Edited by Glenn B Pfeffer. (Pp 88; soft cover; \$38.00) Illinois, USA: American Academy of Orthopaedic Surgeons, 2000. ISBN 089203226X.

In reviewing this book, I was first struck down by the American terminologies, then bogged down by too much information in uninterrupted essay format for two chapters ("Sprains and soft tissue injuries" and "Subtalar injuries"). There was a vast amount of very relevant comprehensive information contained in these sections-for example, different $x$ ray views to request to visualise specific problems, but sadly it was difficult to access in essay format. This was let down the book as a whole, as the last two chapters ("Arthroscopic treatment of Osteochondral lesions and soft tissue impingements" and "Nerve injuries to lateral leg and ankle") were excellently laid out with clear, helpful information for all sports physicians. They were also very well illustrated, including a flow chart for chronic ankle pain management.

I know I am a simple ex GP in sports medicine but, with limited time to read books, I like clear headings, major points highlighted, and tables to compliment the text. I also like pictures; the illustrations in the first two chapters did little, if anything, to clarify the text (reduced size, unclear, black and white anatomy specimen photographs).

Although this book, I think, is aimed at orthopaedic surgeons, it has certainly increased my knowledge and enthusiasm to see chronic ankle problems and I would recommend that anyone serious about sports medicine consider it as a reference book for those difficult ankle problems. If only the authors in the latter part had edited the first two chapters.

\section{Analysis (chapters $1 \in 2$ ) \\ Presentation \\ $6 / 20$ \\ Comprehensiveness \\ Readability \\ $15 / 20$ \\ Relevance \\ $6 / 20$ \\ Evidence basis \\ $12 / 20$}

Total

Analysis (chapters $3 \& 4$ )

Presentation

$16 / 20$

Comprehensiveness

Readability

$15 / 20$

Relevance

Evidence basis

Total

$15 / 20$

$16 / 20$

$78 / 100$

J DUNBAR

Sports Medicine Physician and GP locum, 63 Ochiltree, Dunblane FK15 ODF, UK

\section{NOTES AND NEWS}

\section{Institute of Sports Medicine masters course}

The Working Party of The Institute of Sports Medicine and University College London (UCL) proposed that a new Course in Sport and Exercise Medicine be set up. After eighteen months of intensive preparation, the course started in September 2000. It is based on the Whittington campus of UCL but can draw on the combined resources of the Whittington, Middlesex, Royal Free, and University College Hospitals. The course is designed as an MSc in the Department of Surgery and concentrates on high academic standards, including training in research techniques and a solid foundation in basic science. Nevertheless, there will be a full clinical exposure to all aspects and candidates will be expected to sit for the Diploma in Sports and Exercise Medicine of the Academy of the Medical Royal Colleges.

The Institute have provided an annual bursary to defray the tuition fees of one candidate, and in this millennial year have also awarded a special Millennial Bursary.

\section{Annual awards ceremony}

The Institute of Sport's Annual Awards Ceremony was this year held at The Royal Institution, chaired by Sir David Money-Coutts KCVO. The Guest of Honour was Professor Christopher Llewellyn Smith FRS, the Provost of UCL, who commented in his address that the presence of The Institute physically within the Department of Surgery was an excellent example of the symbiosis between the College and its many guest organisations, each contributing to the good of the others. Three fellowships were awarded by the Institute to Dr Richard Budgett, Director of Medical Services, British Olympic Association and Chairman, BOA Medical Committee (in absentia), Mr Graham Holloway, Consultant in Orthopaedic Surgery and Sports Injuries, Ridgeway and BUPA Cambridge Lea Hospitals, and to Dr Patrick Milroy, Regional Medical Officer to the British Athletics Federation, who gave an entertaining and informative lecture on pitfalls and dilemmas that he had encountered. The Sir Robert Atkins Award was presented to Dr Peter Wilmshurst for services to Diving Medicine, and the recipient of the Millennial Bursary Award, Dr Amir Ali Narvani, was congratulated by the Provost.

\section{Annual symposium}

The Institute's Annual Symposium on "Current Dilemmas, a journey through Sports Medicine, Ethics and the Law" was held jointly with the Section of Sports \& Exercise Medicine of the Royal Society of Medicine on 8 November 2000. A total of 10 speakers of international repute presented papers to a packed Barnes Hall at the Royal Society of Medicine. Details of further such meetings can be obtained by contacting the RSM. 


\section{BASEM Congress 2001}

The BASEM Congress 2001 is to be held at the Vale of Glamorgan Hotel, Golf and Country Club, Wales, from 25-28 October 2001 . Hosted by BASEM Wales, various topics will be covered from the use of padding in Rugby Union to exercise in extremes of temperature. There will be a free afternoon for sporting pursuits and European Club Rugby Union matches are scheduled for that particular weekend. Further details are available from Mrs Sue Roberts, BASEM Company Office, 12 Greenside Avenue, Frodsham, Cheshire WA6 7SA. Tel/fax: 01928732 961; email: basemoffice@compuserve.com.

\section{CALL FOR ABSTRACTS}

The BASEM 2001 congress committee invite submissions of abstracts for the presentation of short papers and posters. All abstracts will be peer reviewed externally and anonymously and those selected may be published in BFSM. Awards will be presented including the BASEM Young Researchers Award, presented to the best paper from an author less than 10 years qualified. Those not selected for oral presentation will be invited to present a poster, or poster only presentations may also be submitted. There will be a poster award presented. Enquiries and submissions should be directed to: Dr Tim Jenkinson, Royal National Hospital for Rheumatic Diseases, Upper Borough Walls, Bath BA1 1RL. Tel: 01225 473428; fax: 01225 473 437; email: Tim.Jenkinson@rnhrdtr.swest.nhs.uk.

AIRCAST TRAVELLING FELLOWSHIP 2001

This fellowship, funded by Aircast Limited Partnership is open to medical practitioners under the age of 40 years, for unpublished work relevant to sport and exercise medicine.
It will allow the holder to spend two weeks in a medical centre of excellence in the United States. Receipted expenses, including the airfare, will be awarded to a maximum of $£ 2000$.

The work should include a structured abstract of approximately 250 words and body text of a standard format (introduction, methods, results, discussion, conclusion, references and an acknowledgement of support received) of approximately 5000 words. The closing date for submission is 1 August 2001, and the holder will be expected to give a 20 minute presentation of his or her work at the BASEM Annual Congress. For further information, please contact the BASEM office.

If you have any notices of forthcoming events or items of news that would be of interest to readers of the journal, please forward them to the editor at the address on the inside front cover.

We regret that figure 2 was omitted from a recent article (BFSM 2001;35:34-7). The figure is reproduced here and we apologise to the authors and readers for this error.

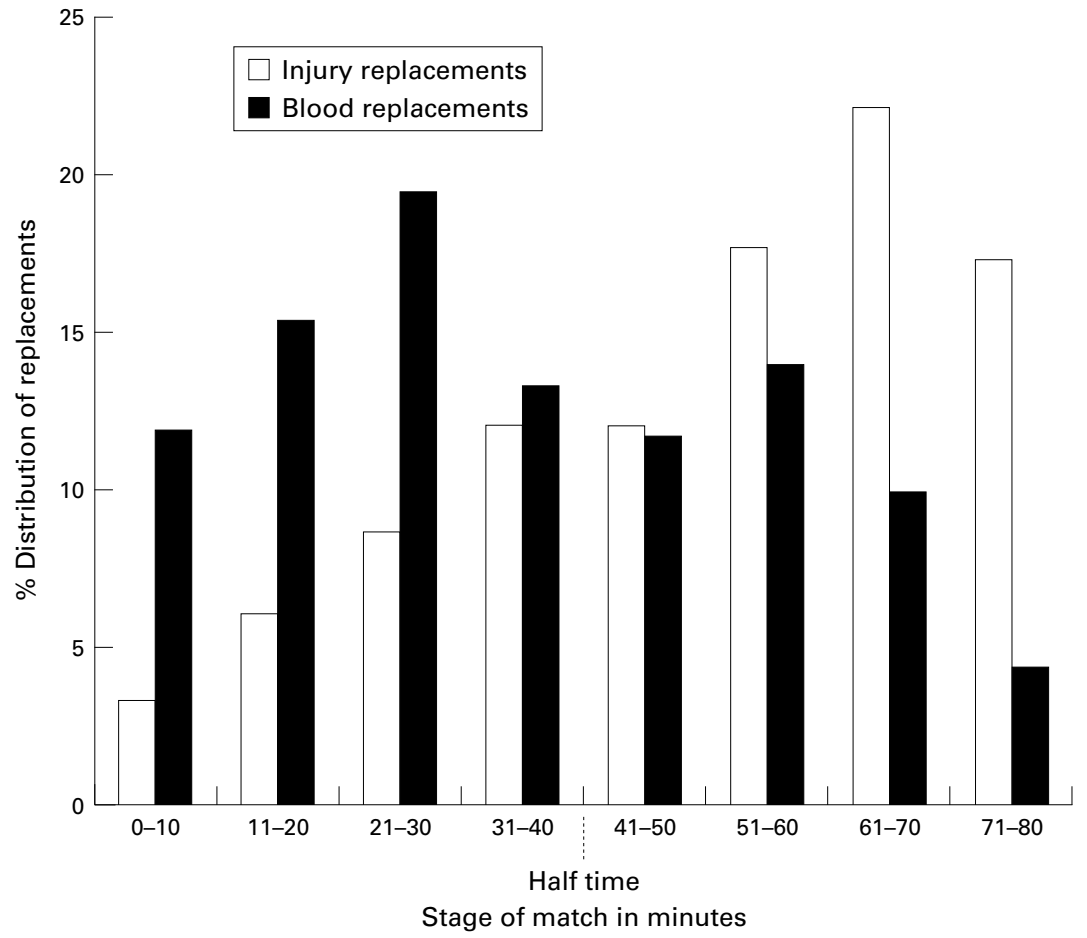

